SIMPÓSIO DOS

PROFISSIONAIS DA (cc) $\mathrm{EY}$

\section{UTILIZAÇÃO DO GOOGLE DRIVE NAS ROTINAS DA SECRETARIA ACADÊMICA DO COTIL}

LUCIANO MUCINI, DOROTHI APARECIDA MACEDO VENÂNCIO, GABRIELLA SIGNORELLI, RENAN VINÍCIUS MEYER, ANA BEATRIZ TEIXEIRA KRONITZKY

COTIL - COLEGIO TECNICO DE LIMEIRA;DIRACA - DIRETORIA ACADEMICA;SACAD - SECAO ACADEMICA

Introdução:

DOI: $10.20396 /$ sinteses.v0i7.11393

A equipe da Secretaria Acadêmica manteve-se inalterada por vários anos, com isso as rotinas foram incorporados pelos funcionários sem a necessidade de registrar os processos pois todos tinham conhecimento dos passos a se seguir. Entretanto, com a renovação quase total já estabelecida pela aposentadoria e/ou transferência de outros setores, a transmissão de conhecimentos faz-se necessária para que os ritos administrativos continuem acontecendo. Com a disponibilização de ferramentas virtuais de compartilhamento de informações, com a possibilidade da participação simultânea e remota, além da construção de um arquivo dessas práticas pode-se ter o envolvimento de todo a equipe para um trabalho mais completo.

\title{
Metodologia:
}

As ferramentas disponíveis no Google Drive foram utilizadas para a construção de 2 arquivos. No ?Documentos Google? fez-se o arquivo ?Respostas do Site?, contendo a padronização no comunicado para os usuários que registram pedidos através do site do Colégio. Em ?Planilhas Google? iniciou-se o registro do documento ?Processos Secretaria Acadêmica?, listando os procedimentos realizados na Seção.

\section{Resultados:}

Os princípios de utilização remota e online do Google Drive contribuíram enormemente para que se obtivesse um resultado tanto próximo de completo como de forma dinâmica pois a possibilidade de se acessar em qualquer lugar e a qualquer momento permitiram que todos os colaboradores pudessem cooperar simultaneamente. No caso do arquivo ?Resposta do Site?, pode-se agilizar as respostas enviadas através do link na página do Colégio, não havendo a necessidade de se construir um texto em cada uma das solicitações. Já na planilha ?Processos Secretaria Acadêmica?, elencamos continuamente o que é feito no Setor. Inicialmente o objetivo seria assegurar o registro dos conhecimentos incorporados pelos pares, antecipando a aposentadoria da Supervisora da Seção. Atualmente o projeto tem sido de grande valia pois está auxiliando enormemente no processo de entendimento da possível migração para o sistema da DAC. Com essas experiências positivas pode-se sugerir que essas ferramentas sejam introduzidas nas rotinas administrativas de forma ampla, facilitando o acesso, o compartilhamento e a construção orgânica e cooperativa de práticas que precisam muitas vezes atender complexidades que requeiram demasiada atenção.

\section{Considerações finais:}

É sabido que a informatização tornou-se algo irreversível. Desta forma sua incorporação aos trabalhos executados é fundamental para que seja algo rotineiro e sem traumas, uma vez que com sua imensa capacidade de fornecer ferramentas para auxiliar nas diversas formas de se lidar com as atividades, pode-se desenvolver efetivas e eficazes práticas para facilitar e agilizar as tarefas do dia-a-dia, dando também a oportunidade da participação coletiva que harmoniza a concordância das ideias.
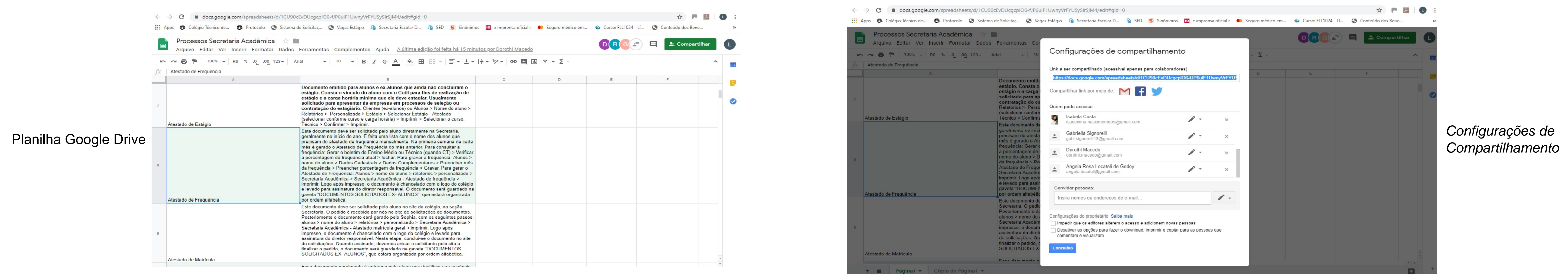

Referências: Ferramentas do Google: Google Drive, Documentos Google, Planilhas Google; Solicitação de Documentos em www.cotil.unicamp.br.

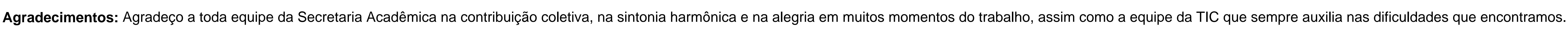

Sínteses: Rev. Eletrôn. SIMTEC, n. 7, e019102, set. 2019 - ISSN 2525-5398 